\title{
Effects of Nutritional Intervention on Weight Gain during Pregnancy
}

\author{
Dr. Bhavana Chauhan \\ S.M.Patel College Of HomeScience, \\ Vallabh Vidyanagar, Gujarat, India
}

\begin{abstract}
Obesity is increasingly common in the obstetric population. Maternal obesity and excess gestational weight gain (GWG) are associated with increased perinatal risk. There is limited published data demonstrating the level of pregnant women's knowledge regarding these problems, their consequences and management strategies.
\end{abstract}

This study was done at Nupoor Nursing Home ISO 9001-2008 Certified hospital, City light, Surat. 100 patients were taken for the study. Out of 100 patients 50 patients have gone through regular nutritional counselling and weight monitoring during pregnancy. Their height, pre pregnancy weight, BMI, total weight gain during pregnancy, dietary habits etc. were observed and compared with control group.

And finding suggests that there is a huge impact of nutrition counselling on overall weight gain during pregnancy.

\section{INTRODUCTION}

Overweight and obesity are common problems with an increasing worldwide incidence [1]. Recent Australian data showed that $50 \%$ of pregnant women were overweight or obese and in the United States $36 \%$ of women were obese $[2,3]$.

Maternal obesity and excessive gestational weight gain (GWG) have well recognized associations with pre-eclampsia, gestational diabetes mellitus (GDM), instrumental or operative delivery, failed induction, fetal macrosomia, neonatal hypoglycaemia, perinatal mortality and infant and childhood obesity [4-5]. In addition, maternal obesity is the single most common modifiable factor in stillbirth in the developed world [6].

There is limited published data assessing the relationship between a woman's actual and perceived Body Mass Index (BMI) in pregnancy, and the effect this has on GWG. It has been demonstrated that overweight and obese pregnant women are less likely than women of normal weight to correctly assess their own BMI [7], and that overweight women who underestimate their BMI are more likely to gain excess weight in pregnancy [8]. It is normal for women to gain some weight during pregnancy due to the growth of the fetus, placenta and amniotic fluid. However, too much extra weight during pregnancy can lead to adverse outcomes for the mother and/or baby.

In line with the worldwide increase of obesity, maternal obesity is becoming more prevalent. Maternal obesity is a major risk factor in the short term for both maternal and foetal complications, including maternal and foetal mortality, miscarriages, gestational diabetes mellitus (GDM), pregnancyinduced hypertensive disorders, macrosomia, and caesarean sections. [9]

The amount of weight that a woman can expect to gain during pregnancy varies depending on the woman's existing weight and height. This document 
provides guidance to support optimal weight gain for the individual woman during pregnancy.

The American Institute of Medicine (IOM) first suggested guidelines for weight gain during pregnancy in 1990, based on a woman's prepregnancy Body Mass Index (BMI). Specifically, it recommended that normal weight women (BMI 19.8$26 \mathrm{~kg} / \mathrm{m}^{2}$ ) gain $11.5-16 \mathrm{~kg}$, underweight women (BMI $<19.8 \mathrm{~kg} / \mathrm{m}^{2}$ ) gain $12.5-18 \mathrm{~kg}$, overweight women
(BMI 26.1-29 kg/m²) gain 7-11.5 kg, and obese women $\left(\mathrm{BMI}>29 \mathrm{~kg} / \mathrm{m}^{2}\right)$ gain at least $6.8 \mathrm{~kg}$. [10.11]

The eating for two is not a sound practice. Eating the same quantity but most nutritional balanced diet should be emphasized during antenatal education. [12] Healthy eating is especially important during pregnancy as it supports optimal fetal growth and development. Physical activity along with good nutrition will contribute to a healthy pregnancy weight.

Table: 1 OPTIMAL WEIGHT GAIN DURING PREGNANCY

Recommendations for total and average rate of weight gain during pregnancy, by pre-pregnancy BMI

\begin{tabular}{|l|l|l|}
\hline \multicolumn{1}{|c|}{$\begin{array}{c}\text { Pre-pregnancy BMI } \\
\left(\mathrm{kg} / \mathrm{m}^{2}\right)\end{array}$} & \multicolumn{1}{|c|}{$\begin{array}{c}\text { Total weight gain } \\
\text { range } \\
(\mathrm{lbs})\end{array}$} & \multicolumn{1}{|c|}{$\begin{array}{c}\text { Rates of weight gain 2nd and 3rd } \\
\text { trimester } \\
(\text { mean range in lb/week })^{1}\end{array}$} \\
\hline Underweight $(<18.5)$ & $28-40$ & $1 \mathrm{lb}$ per week \\
\hline $\begin{array}{l}\text { Healthy weight } \\
(18.5-24.9)\end{array}$ & $25-35$ & $1 \mathrm{lb}$ per week \\
\hline Overweight $(25.0-29.9)$ & $15-25$ & $0.6 \mathrm{lb}$ per week \\
\hline Obese $(\geq 30.0)$ & $11-20$ & $0.5 \mathrm{lb}$ per week \\
\hline
\end{tabular}

1 ref: IOM - according to FOGSI criteria.

\section{MATERIALS \& METHODS}

This study was aimed to determine the effectiveness of the planned teaching in relation to dietary intake and control of excess weight gain during pregnancy.

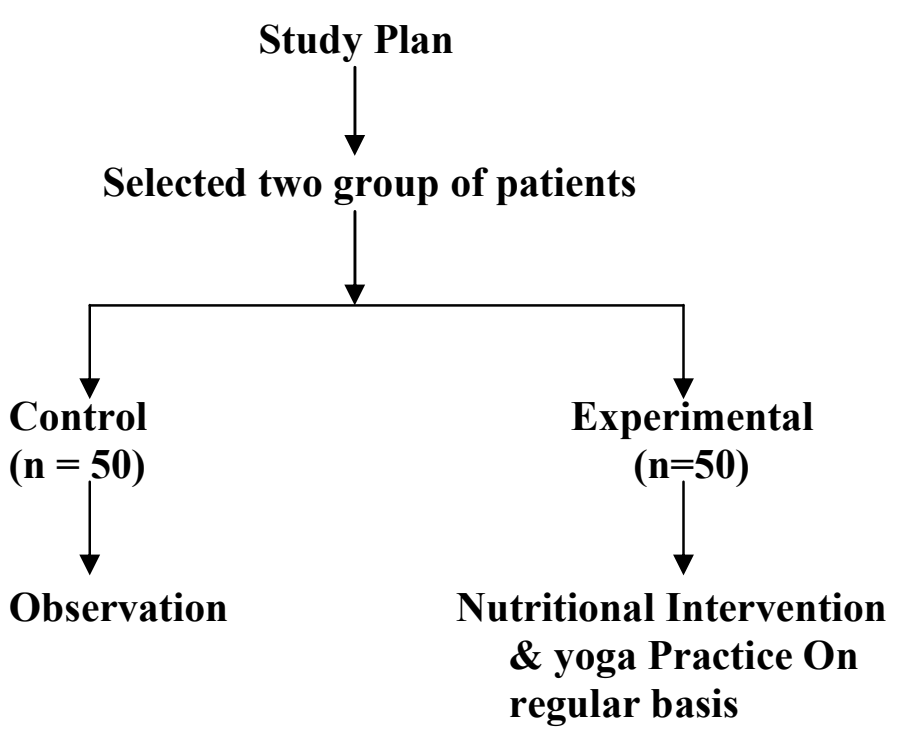

\section{Sampling Procedure}

The researcher sorted out the pregnant women in two groups. One group is control group who has not gone through any dietary intervention during pregnancy and other is experimental group who was done regular diet counselling and has followed the nutritional advice during pregnancy.

\section{Tools of Data Collection}

\section{Anthropometric measurements}

Include the weight, height and calculation of BMI. These measurements were carried out upon booking visit at registration within few weeks following conception. 


\section{RESULTS AND DISCUSSIONS}

This chapter deals with the analysis and interpretation and discussion of data collected from 100 antenatal mothers from Nursing Home., Surat.

The subjects were selected by experimental sampling method.

Data was collected using anthropometric measurements of the subjects and their regular nutritional intervention during pregnancy. The data was analysed to find out the difference in weight gain during pregnancy through regular intervention between control and experimental group of pregnant ladies.

Analysis of data was done in accordance with the objectives of the study.

\section{Objective of the study}

(1) To determine the effects of nutritional intervention in pregnancy on weight gain during pregnancy.

The collected data has been analysed and presented in various sections:

1. Data and analysis related to anthropometric measurements

2. Data and analysis related to dietary behaviour

Table - 1 Percentage of weight gain during pregnancy

\begin{tabular}{|c|c|c|}
\hline $\begin{array}{c}\text { Weight Gain } \\
\text { Range }\end{array}$ & Control Group & $\begin{array}{c}\text { Experimental } \\
\text { Group }\end{array}$ \\
\hline Under Range & $20 \%$ & $43 \%$ \\
\hline Out Of Range & $30 \%$ & $7 \%$ \\
\hline
\end{tabular}

Above table shows that the $20 \%$ of the subjects in control group had weight gain under the range and $30 \%$ of subjects has weight gain out of range. While in experimental group $43 \%$ of the subjects had weight gain under the range and only $7 \%$ of subjects have weight gain out of range. It indicates that on experimental group subjects gained more their weight in range.

\section{Fig: 1 Percentage of subjects who gained weight}

\section{$\%$ Of Subjects Of Weight Gain Range}

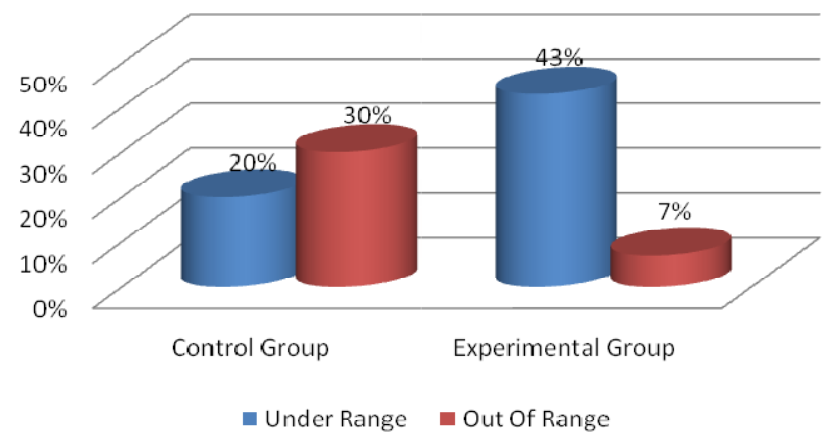

Table - 2 Relation between Snacks consumed Frequently / Non Frequently With Weight

\begin{tabular}{|l|l|c|l|l|}
\hline \begin{tabular}{l} 
Weight $\begin{array}{c}\text { Gain } \\
\text { Range }\end{array}$ \\
\cline { 2 - 5 }
\end{tabular} & \multicolumn{2}{|c|}{$\begin{array}{c}\text { Control Group } \\
\text { Snacks }\end{array}$} & \multicolumn{2}{c|}{$\begin{array}{c}\text { Experimental } \\
\text { Group } \\
\text { Snacks }\end{array}$} \\
\cline { 2 - 5 } & Frequent & $\begin{array}{c}\text { Non } \\
\text { Frequent }\end{array}$ & Frequent & $\begin{array}{c}\text { Non } \\
\text { Frequent }\end{array}$ \\
\hline $\begin{array}{l}\text { Under } \\
\text { Range }\end{array}$ & $17 \%$ & $3 \%$ & $43 \%$ & $0 \%$ \\
\hline $\begin{array}{l}\text { Out Of } \\
\text { Range }\end{array}$ & $30 \%$ & $0 \%$ & $7 \%$ & $0 \%$ \\
\hline
\end{tabular}

Above table shows that from control group $47 \%$ of subjects were having snacks frequently. Amongst them $17 \%$ of subjects' weight gain was in range and $30 \%$ of subjects' weight gain was out of range, while $3 \%$ of subjects were having snacks non frequently and their weight gain was in range.

For experimental group, $50 \%$ of subjects were having snacks frequently. Amongst them 43\% of subjects' weight gain was in range and $7 \%$ of subjects' weight gain was out of range, while none is having snack non frequently. It means that all are having meals $>3$ in a day.

So it indicates that in experimental group though they were having snack frequently their weight gain was in range. 
Fig - 2 Relation between snacks and weight gain

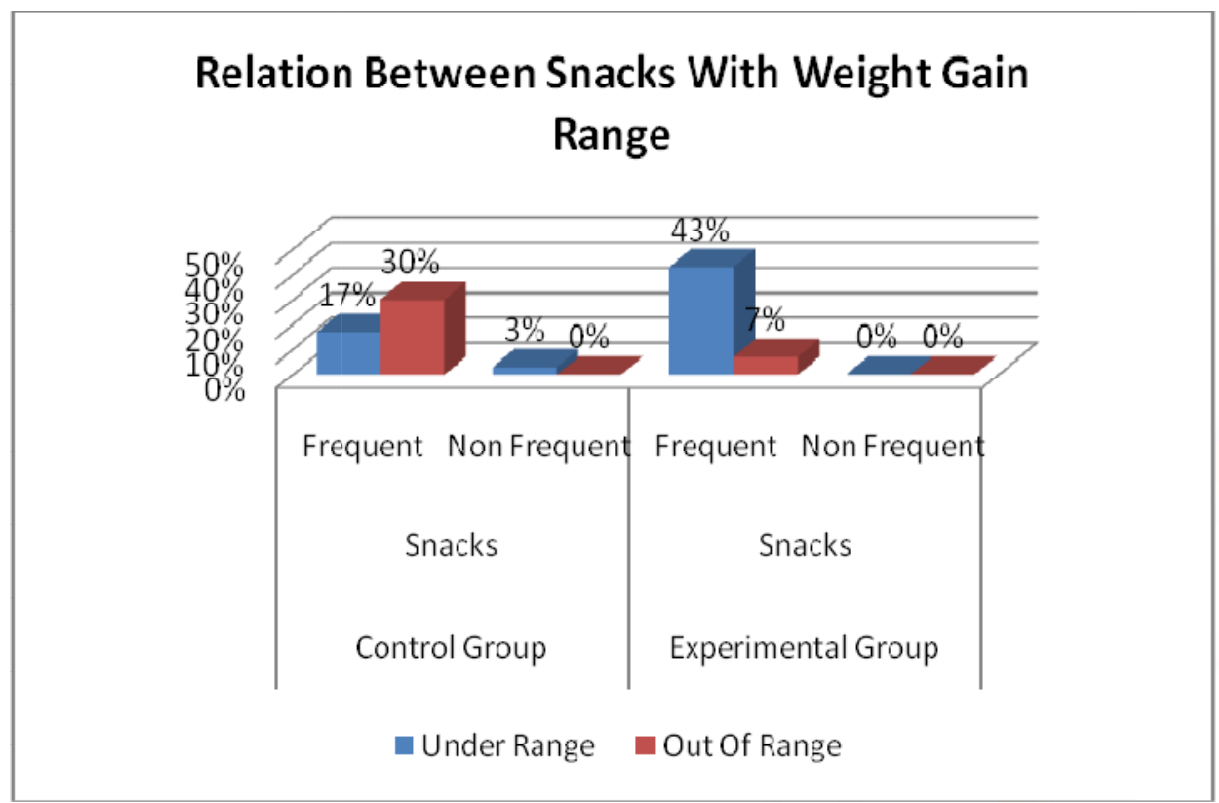

Table - 3: Relation between Desserts with Weight Gain Range

\begin{tabular}{|c|c|c|c|c|}
\hline \multirow{2}{*}{$\begin{array}{c}\text { Weight } \\
\text { Gain } \\
\text { Range }\end{array}$} & \multicolumn{2}{|c|}{$\begin{array}{c}\text { Control Group } \\
\text { Desserts }\end{array}$} & \multicolumn{2}{c|}{$\begin{array}{r}\text { Experimental Group } \\
\text { Desserts }\end{array}$} \\
\cline { 2 - 5 } & Frequent & $\begin{array}{c}\text { Non } \\
\text { Frequent }\end{array}$ & Frequent & $\begin{array}{c}\text { Non } \\
\text { Frequent }\end{array}$ \\
\hline $\begin{array}{c}\text { Under } \\
\text { Range }\end{array}$ & $11 \%$ & $9 \%$ & $8 \%$ & $35 \%$ \\
\hline $\begin{array}{c}\text { Out Of } \\
\text { Range }\end{array}$ & $17 \%$ & $13 \%$ & $2 \%$ & $5 \%$ \\
\hline
\end{tabular}

From table 3 we can see that the control group total $28 \%$ of subjects were having desserts frequently. Amongst them only $11 \%$ of subjects' weight gain was in range and $17 \%$ of subjects' weight gains were out of range. While $22 \%$ of subject were having desserts non frequently. Amongst them 9\% of subjects' weight gain was in range and $13 \%$ of subjects' weight gain was out of range.

In control group total $10 \%$ of subjects were having desserts frequently. Amongst them only $8 \%$ of subjects' weight gain was in range and $2 \%$ of subjects' weight gains were out of range. While $40 \%$ of subject were having desserts non frequently. Amongst them $35 \%$ of subjects' weight gain was in range and $5 \%$ of subjects' weight gain was out of range. So it indicates that in control group subjects were having desserts more frequently and their weight gain was also out of range.

\section{Fig- 3 Relation between desserts and weight gain} Relation Between Desserts With Weight Gain
Range

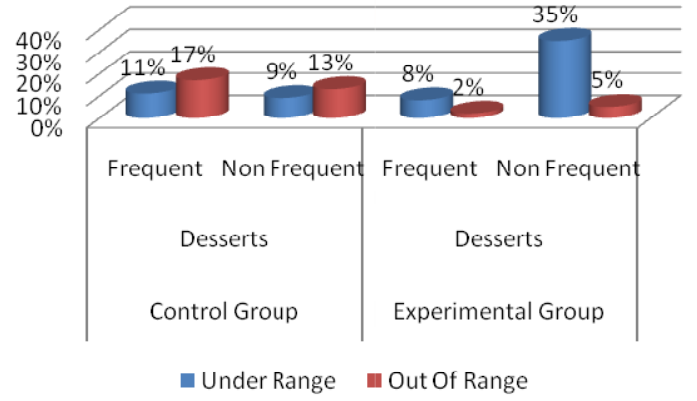


Fig- 4 Relation between consumption of Oils with weight gain

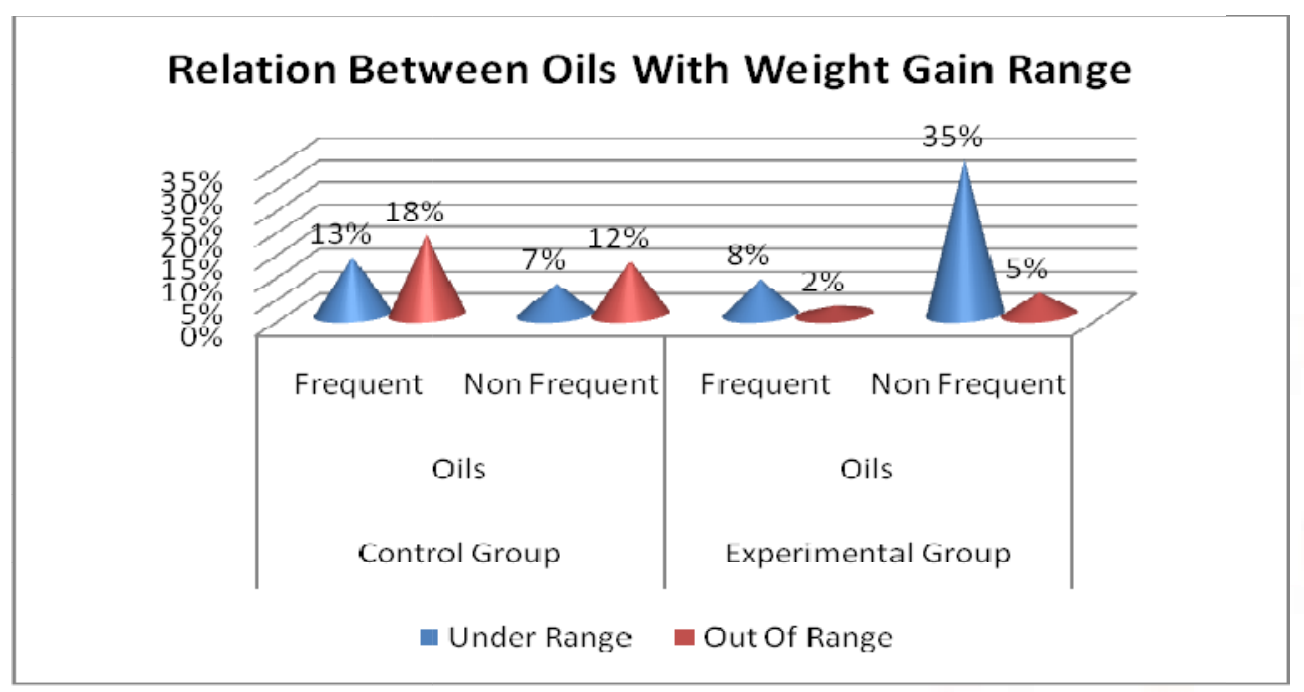

Above figure shows that from control group 31\% of subjects were having oily food frequently. Amongst them $13 \%$ of subjects' weight gain was in range and $18 \%$ of subjects' weight gain was out of range, while $19 \%$ of subjects were having oily food non frequently. Amongst them $7 \%$ of subjects' weight gain was in range and $12 \%$ of subjects' weight gain was out of range.

For experimental group, $10 \%$ of subjects were having oily food frequently. Amongst them $8 \%$ of subjects' weight gain was in range and $2 \%$ of subjects' weight gain was out of range, while $40 \%$ of subjects were having oily food non frequently. Amongst them 35\% of subjects' weight gain was in range and $5 \%$ of subjects' weight gain was out of range.

It indicates that in control group subjects were having oily food more than experimental group and their weight gain range was also more.

\section{FINDINGS AND CONCLUSION}

Education in nutrition is essential of component of Antenatal care activity. It is more effective during pregnancy as the pregnant mothers are more respective in this period.

It may result in immediate possible change in dietary practices as pregnant mothers are convinced of having better nutritious food with no extra cost but little efforts of modification in dietary practice to control excess weight gain.

\section{Findings related to anthropometric measurements.}

In experimental group weight gain of subjects was found to be $43 \%$ less in comparison to the control group. Thus, nutritional intervention and yoga can directly affect on weight gain during pregnancy and weight of the baby.

\section{Findings related to dietary behaviour.}

Subjects in control group who were having snacks frequently they are more in weight gainout of range in comparison to under range. While in experimental group subjects who were having snacks frequently they are more in under weight gain in compare to out of range weight gain.

So frequent eating can increase the weight gain but by proper nutritional intervention the weight gain can be in limits.

In control group more subjects were having desserts frequently than the experimental group. And their weight gain was also out of range while experimental group subject's weight gain was in range.

Same as desserts, the control group subjects were having more of oily and fried foods frequently compared to the experimental group. And their weight gain was also out of range while experimental group subjects' weight gain was in range. 
Thus, we can conclude that proper nutritional intervention can improve the sense of healthy eating.

\section{CONCLUSION}

Nutritional education on diet during pregnancy is an effective step in improving and maintaining the nutritional status of pregnancy. On the basis of knowledge and understanding respondents can adopt useful food habits and thus actively participate in promotion of her own health status. It is clear from the present study that nutritional intervention is the most important part of this stage of life cycle to remain fit and healthy, reduce the complications and to avoid overweight. Hence, the awareness of regarding nutrition counseling during pregnancy should be increased. In hospitals and nursing homes pregnancy awareness programmes, nutritional counseling should be done regularly. Patients can get benefits out of it and can improve their health status. Thus have safe and healthy pregnancy.

\section{REFERENCES:}

1) World Health Organization: Obesity: preventing and managing the global epidemic. Report of a WHO consultation (WHO Technical Report Series 894). Geneva Switzerland: 1999.

2) Dodd JM, Grivell RM, Nguyen AM, Chan A, Robinson JS: Maternal and perinatal health outcomes by body mass index category. Aust $N Z$ J Obstet Gynaecol 2011, 51:136-140.

3) Flegal KM, Carroll MD, Kit BK, Ogden CL: Prevalence of obesity and trends in the distribution of body mass index among US adults, 1999-2010.

4) JAMA 2012, 307:491-497.

5) Cedergren $M$ : Effects of gestational weight gain and body mass index on obstetric outcome in Sweden. Int J Gynaecol Obstet 2006, 93:269-274.

6) Rode L, Kjaergaard H, Ottesen B, Damm P, Hegaard HK: Association between gestational weight gain according to body mass index and postpartum weight in a large cohort of Danish women.

7) Matern Child Health J 2012, 16:406-413

8) Flenady V, Middleton P, Smith GC, Duke W, Erwich JJ, Khong TY, Neilson J, Ezzati M, Koopmans L, Ellwood D, et al.: Stillbirths: the way forward in high-income countries.
9) Lancet 2011, 377:1703-1717.

10) Callaway LK, O'Callaghan MJ, McIntyre HD: Barriers to addressing overweight and obesity before conception.

11) Med J Aust 2009, 191:425-428.

12) Herring SJ, Oken E, Haines J, Rich-Edwards JW, Rifas-Shiman SL, Kleinman Sc DK, Gillman MW: Misperceived pre-pregnancy body weight status predicts excessive gestational weight gain: findings from a US cohort study. 